\title{
Unusual Presentation of Laryngeal Cavernous Hemangioma
}

\author{
1Jaini Lodha, ${ }^{2}$ Arpit Sharma, ${ }^{3}$ Jyoti Dabholkar, ${ }^{4}$ Nitish Virmani
}

\begin{abstract}
Cavernous hemangioma is a rare tumor of the adult larynx. These hemangiomas are confined to the larynx and generally asymptomatic. We present a rare case of a huge cavernous hemangioma in a 22-year-old patient who presented with stridor and a huge swelling in the neck, of acute onset. Detailed evaluation including $70^{\circ}$ Hopkins laryngoscopy, contrastenhanced computed tomography (CT) scan and magnetic resonance imaging (MRI) revealed a vascular malformation with both intra- and extralaryngeal components. The typical findings of hemangioma with its management are highlighted in this article. Postoperatively, patient's voice improved and the stridor was relieved.
\end{abstract}

Keywords: Cavernous hemangioma, $\mathrm{CO}_{2}$ Laser, Stridor.

How to cite this article: Lodha J, Sharma A, Dabholkar J, Virmani N. Unusual Presentation of Laryngeal Cavernous Hemangioma. Int J Phonosurg Laryngol 2015;5(2):67-69.

\section{Source of support: Nil}

\section{Conflict of interest: None}

\section{INTRODUCTION}

Benign neoplasms of the larynx are infrequent. Almost $95 \%$ of the benign neoplasms are papillomas; the rest comprise of oncocytic tumors, pleomorphic adenomas, lymphangiomas, neurofibromas, fibromatosis, paragangliomas, rhabdomyomas and hemangiomas. ${ }^{1}$

Cavernous hemangiomas are very rare in the adult larynx. It is defined as a vascular malformation consisting of abnormal, dilated vessels. In adults, these tumors generally lie silent over a period of many years and do not warrant treatment till the time it causes obstructive symptoms like dyspnea, dysphagia. Eighty percent of these lesions lie in supraglottis, followed by glottis and subglottis. ${ }^{1}$

We hereby present a rare case of a young 22-yearold female with a huge cavernous hemangioma of the supraglottis with a massive extralaryngeal extension

\footnotetext{
${ }^{1}$ Senior Resident, ${ }^{2}$ Assistant Professor

${ }^{3}$ Professor and Head, ${ }^{4}$ Postgraduate Resident

${ }^{1-4}$ Department of ENT, Seth GS Medical College and KEM Hospital, Mumbai, Maharashtra, India

Corresponding Author: Jaini Lodha, Senior Resident Department of ENT, Seth GS Medical College and KEM Hospital Mumbai, Maharashtra, India, Phone: 9820772383, e-mail: jainilodha@gmail.com
}

presenting with stridor of recent onset, who was managed successfully surgically without any complications.

\section{CASE REPORT}

A 22-year-old woman presented to the emergency room with a long-standing swelling in the anterior neck region (around 5 years). The swelling had been painless and nonprogressive until 3 days back when she developed a sudden increase in the size of swelling associated with severe pain. She also developed hoarseness and difficulty in breathing, especially in the supine position. There was no history of fever or an inciting trauma to the neck. The patient did not give any history of sudden phonotrauma. On physical examination, the patient was tachypneic and had stridor. There was a $7 \times 5 \mathrm{~cm}$ swelling over the anterior neck extending between the anterior margins of bilateral sternocleidomastoid muscles and superiorly extending up to the level of hyoid bone (Fig. 1). The swelling moved with deglutition but not on protrusion of tongue. It was soft, tender, nonpulsatile and rubbery to touch. Hopkin's $70^{\circ}$ laryngoscopy revealed a submucosal bluish bulge involving the right aryepiglottic fold and right false vocal fold (Fig. 2).

With the possibility of a vascular mass in mind, contrast-enhanced computed tomography (CT) and magnetic resonance imaging (MRI) scans of the neck was ordered. Computed tomography scan revealed heterogeneous lobulated swelling with serpiginous enhancing vessels in the neck and in the larynx, at the

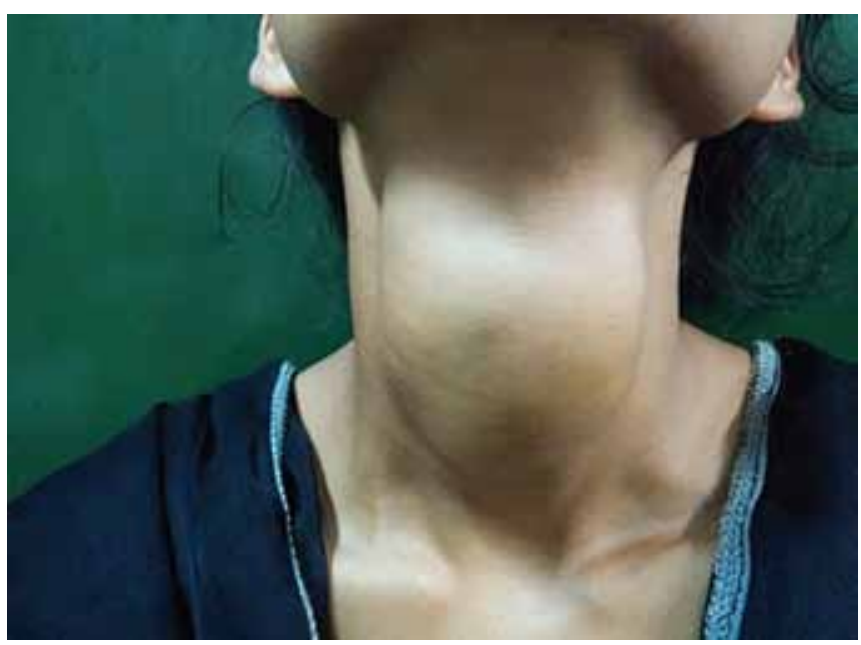

Fig. 1: Huge anterior neck swelling extending between the two sternocleidomastoid heads 


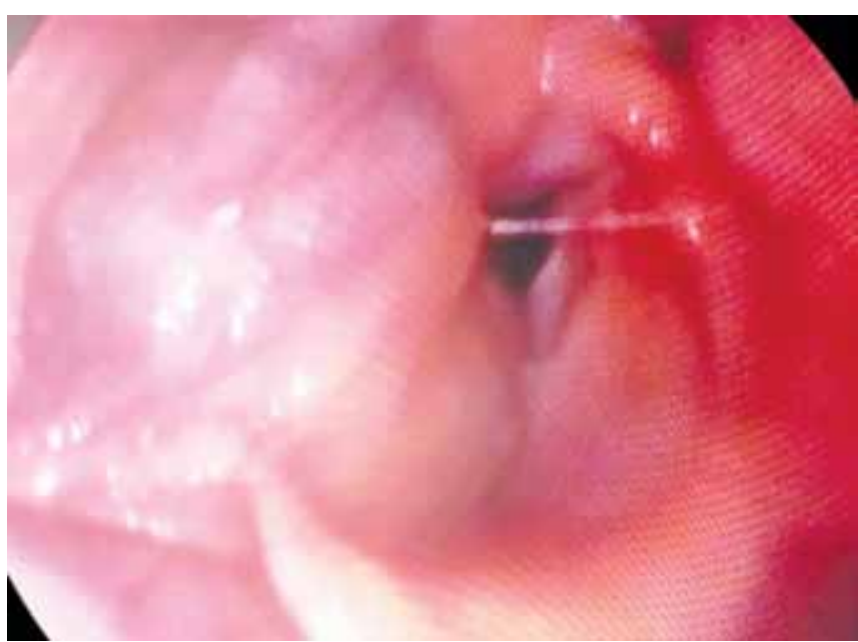

Fig. 2: Submucosal bluish bulge involving the right arytenoid, aryepiglottic fold and false cord

level of false cord obscuring the airway (Fig. 3) and MRI scan revealed $\mathrm{T} 2$ hyperintense lesion and $\mathrm{T} 1$ hypointense multilobulated lesion $7.5 \times 3.4 \times 2.4 \mathrm{~cm}$ displacing the

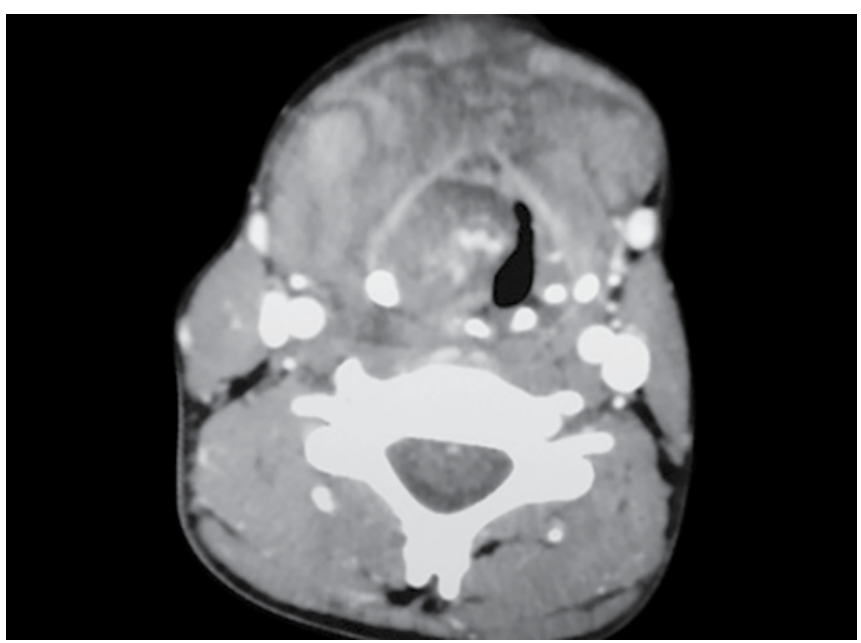

Fig. 3: Axial section of contrast-enhanced CT neck showing heterogeneous lobulated swelling with serpiginous enhancing vessels at the false cord level obscuring the larynx

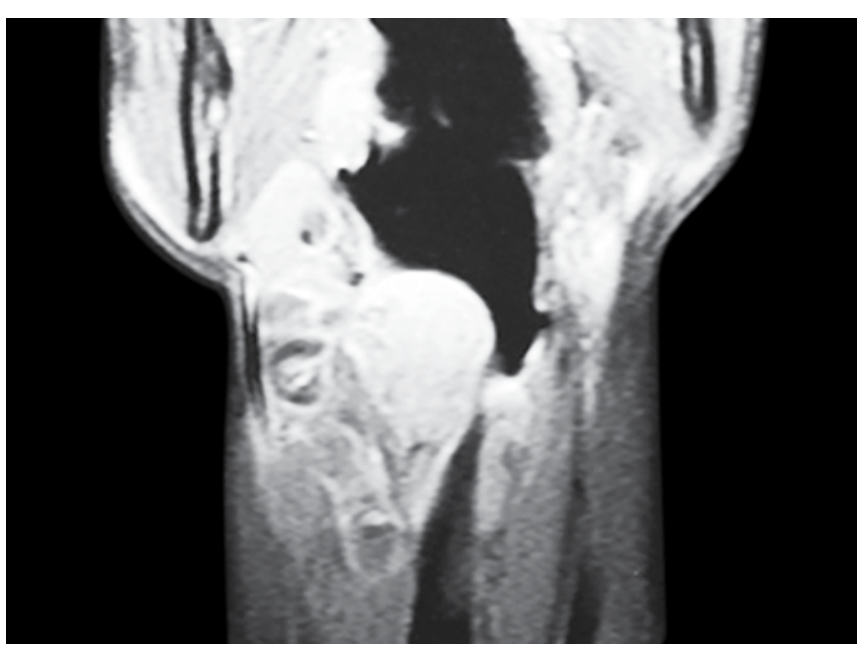

Fig. 4: Coronal T2 MRI section demonstrating hyperintense lesion in the larynx extending into the neck epiglottis, involving the thyroid cartilage and causing airway occlusion at the level of C4 (Fig. 4). The patient was posted for a combined external and transoral excision of the mass. Patient was intubated with a small sized endotracheal tube. A horizontal neck incision was taken and strap muscles were divided in midline and retracted to expose the vascular mass (Fig. 5A). Thyroid gland was found to be displaced toward left. Right recurrent laryngeal nerve was identified and preserved. The mass was separated from the thyroid and cricoid cartilage and excised (Fig. 5B) and a part of the vascular mass extending into the larynx was tackled via exposing the larynx using a Kleinsasser laryngoscope. With the bulge still present, a small incision was made on the right aryepiglottic fold using $\mathrm{CO}_{2}$ laser and vaporization of the mass was done achieving adequate hemostasis.

Patientcould besuccessfully extubated. Postoperatively, she did not have any breathing difficulty and her voice improved considerably. Postoperative histopathology report revealed cavernous hemangioma. A follow-up Hopkin's $70^{\circ}$ laryngoscopy revealed normal endolarynx at 3 months follow-up period.
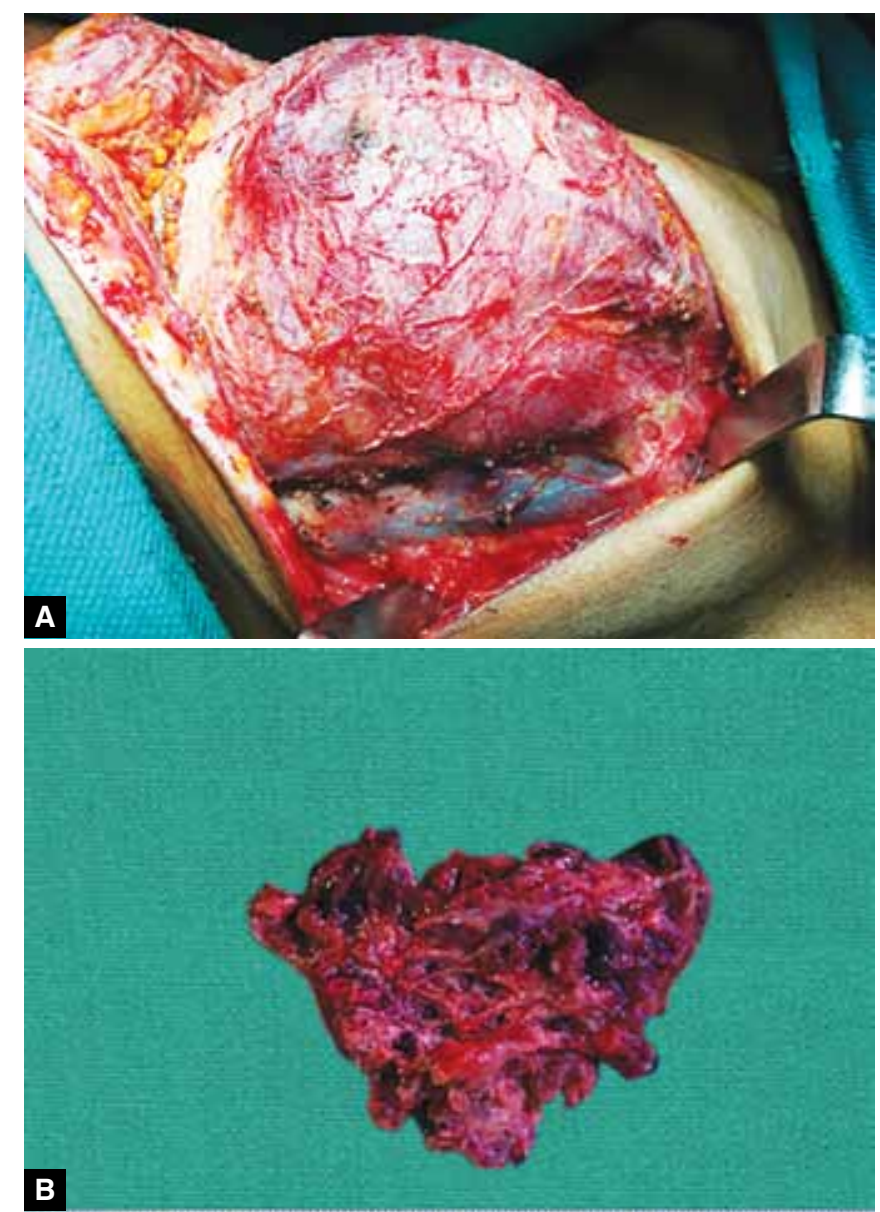

(IT)

Figs 5A and B: (A) Intraoperative picture showing the huge cavernous hemangioma and (B) specimen of hemangioma excised 


\section{DISCUSSION}

Laryngeal hemangiomas are broadly classified into infantile and adult types. This classification was first proposed by Sweeter in 1921. Infantile hemangiomas are associated with multiple skin and gastrointestinal manifestations. These hemangiomas in the neonatal period can be associated with dyspnea and stridor, and they generally involute by 5 years of age.

Adult hemangiomas in contrast do not involute spontaneously. They are more commonly of the cavernous type and are mostly located at or above the level of vocal cords.

In our case, the location of the huge cavernous hemangioma was supraglottis and in addition it was also spreading extralaryngeally. The important point clinically in this case was to differentiate it from a thyroid swelling. Since the patient had a long-standing history of anterior neck selling before the acute symptoms developed, the first diagnosis would have been of a thyroid swelling. But the rubbery feel on palpation alongwith a bluish bulge on endoscopy, clinched the diagnosis of hemangioma of larynx, which was further confirmed by imaging. On MRI, cavernous hemangiomas appear as well-demarcated, homogeneously hyperintense lesions on T2-weighted images, and hypointense on T1-weighted images and on contrast-enhanced T1-weighted images, all of these lesions have homogenous enhancement. ${ }^{2}$

Sudden onset hemorrhage in a long-standing hemangioma caused the acute symptoms in our case and tracheostomy could be avoided in this case because of the rapid and timely diagnosis and intervention.

The surgical approach was combined extra- and intralaryngeal because of the size of the hemangioma. Bridger and associates recommended that adult laryngeal hemangiomas should be left alone if there are no symptoms. $^{3}$

If there are obstructive symptoms (like in our case), like sudden stridor and breathing difficulty caused by rapid growth (because of the internal hemorrhage), active intervention is warranted. The treatment options of laryngeal and upper airway hemangiomas include steroid injection, systemic steroid therapy, beta blockers therapy, laser ablation and surgical removal. ${ }^{4,5}$ Radiotherapy use for hemangiomas is now obsolete, since radiation therapy has a host of side effects. Use of beta blocker like propranolol is the modality of choice in infantile hemangiomas and has been extensively studied in the recent past. $\mathrm{CO}_{2}$ laser is the treatment of choice for adult laryngeal hemangiomas. ${ }^{6}$ In cases of extended hemangiomas, staged procedures may be required. Lucioni et $\mathrm{al}^{7}$ in their 3-year study of use of $\mathrm{CO}_{2}$ Laser for hemangioma cases, found it successful in five out of six cases. ${ }^{7}$

\section{CONCLUSION}

To summarize, one needs to be aware of the following facts:

- Adult laryngeal hemangiomas, although silent for many years, can rapidly grow and cause obstructive symptoms

- Bluish submucosal bulge on endoscopy clinches the diagnosis

- Imaging confirms the diagnosis

- Timely diagnosis and intervention can avoid tracheostomy

- Surgery with $\mathrm{CO}_{2}$ laser is feasible option.

\section{REFERENCES}

1. Grant DG, Birchall MA, Bradley PJ. Surgery for benign tumors of the adult larynx. In: Remade M, Eckel HE, editors. Surgery of Larynx and Trachea. Berlin, Heidelberg: Springer; 2010. p. 91-111.

2. Sohn CH, Kim SP, Kim IM, Lee JH, Lee HK. Characteristic MR imaging findings of cavernous hemangiomas in the cavernous sinus. Am J Neuroradiol 2003 Jun-Jul;24(6):1148-1151.

3. Bridger GP, Nassar VH, Skinner HG. Hemangioma in the adult larynx. Arch Otolaryngol 1970 Nov;92(5):493-498.

4. Ibrahimov M, Sari E, Yener M, Karaman E, Enver O. Cavernous hemangioma of the larynx. J Craniofac Surg 2013 Mar;24(2):687.

5. Huang CM, Lee KW, Huang CJ. Radiation therapy for life-threatening huge laryngeal hemangioma involving pharynx and parapharyngeal space. Head Neck 2013 Apr;35(4):E98-E101.

6. Bielamowicz S, Stager S, Soofer S. Vocal fold hemangioma. Ear Nose Throat J 2000 Apr;79(4):230.

7. Lucioni M, Marioni G, Della Libera D, Rizzotto G. Adult laryngeal hemangioma $\mathrm{CO}_{2}$ laser excision: a single institution 3-year experience (Vittorio Veneto 2001-2003). Acta Otolaryngol 2006 Jun;126(6):621-626. 